\title{
The mucosal addressin cell adhesion molecule antibody PF-00547,659 in ulcerative colitis: a randomised study
}

\author{
Séverine Vermeire, ${ }^{1}$ Subrata Ghosh, ${ }^{2}$ Julian Panes, ${ }^{3}$ Jens F Dahlerup, ${ }^{4}$ \\ Andreas Luegering, ${ }^{5}$ Jana Sirotiakova, ${ }^{6}$ Ulrike Strauch, ${ }^{7}$ Gary Burgess, \\ Jacqueline Spanton, ${ }^{8}$ Steven W Martin, ${ }^{8}$ Wojciech Niezychowski ${ }^{8}$
}

\section{${ }^{1}$ Department of}

Gastroenterology, University Hospitals Leuven, Leuven,

Belgium

${ }^{2}$ Division of Gastroenterology, University of Calgary, Calgary,

Alberta, Canada

${ }^{3}$ Department of

Gastroenterology, Hospital Clinic of Barcelona, Barcelona,

CIBERehd, Spain

${ }^{4}$ Department of Medicine V

(Hepatology and

Gastroenterology), Aarhus

University Hospital, Aarhus,

Denmark

${ }^{5}$ Department of Medicine B University of Münster, Germany ${ }^{6}$ Internal Clinic Department of Clinical Pharmacology, Nitra, Slovakia

${ }^{7}$ Department for Internal Medicine I, University Hospital, Regensburg, Germany

${ }^{8}$ Pfizer Ltd, Sandwich, Kent, UK

\section{Correspondence to}

Dr Séverine Vermeire,

Department of

Gastroenterology, University

Hospital Gasthuisberg, Herestraat 49, 3000 Leuven,

Belgium; severine.vermeire@ uz.kuleuven.ac.be

Writing assistance: Editorial support with the drafting of this manuscript was provided by Samantha Stanbury PhD and Louise Norbury MSc (FireKite, UK), and funded by Pfizer Inc. Data analysis was led by Jacqueline Spanton, Steven W. Martin and Wojciech Niezychowski at Pfizer Ltd.

Revised 4 January 2011 Accepted 7 January 2011 Published Online First 11 February 2011

\section{ABSTRACT}

Background and aims Leucocyte migration to gut mucosa, mediated by integrin binding to mucosal addressin cell adhesion molecule (MAdCAM), is a promising target for therapeutic intervention in inflammatory bowel disease. This first-in-human study of a monoclonal antibody to MAdCAM, PF-00547,659, aimed to explore the safety and preliminary efficacy of this gut-specific mechanism in ulcerative colitis. Methods In this randomised, double-blind placebocontrolled study, 80 patients with active ulcerative colitis received single or multiple (three doses, 4-week intervals) doses of PF-00547,659 0.03-10 mg/kg IV/SC, or placebo. Safety was assessed by adverse events, laboratory tests, and immunogenicity. Exploratory efficacy analyses were based on Mayo score and endoscopic responder rates at weeks 4 and 12. Faecal calprotectin was quantified as a measure of disease activity, and the number of $\alpha_{4} \beta_{7}{ }^{+}$lymphocytes was measured to demonstrate drug activity.

Results No obvious drug-related side effects were observed in the PF-00547,659 group, while patient numbers, especially those fully exposed, were small. Overall responder/remission rates at 4 and 12 weeks were $52 \% / 13 \%$ and $42 \% / 22 \%$, respectively with combined PF-00547,659 doses compared with 32\%/11\% and $21 \% / 0 \%$, respectively with placebo. Equivalent endoscopic responder rates were $50 \%$ and $42 \%$ versus $26 \%$ and $29 \%$, respectively. Faecal calprotectin levels decreased to a greater extent with PF-00547,659 than placebo (week 4: $63 \%$ vs 18\%). Despite variability, there was a trend for an increase in $\alpha_{4} \beta_{7}{ }^{+}$lymphocytes in patients receiving PF-00547,659.

Conclusions The favourable short-term safety profile and preliminary efficacy findings for PF-00547,659 in this first-in-human study pave the way for further investigation in larger trials, to establish the role of PF-00547,659 in ulcerative colitis treatment.

Trial Register No: NCT00928681.

\section{Significance of this study}

What is already known about this subject?

- Despite the fact that biological therapies targeting tumour necrosis factor $\alpha$ (TNF $\alpha$ ) have significantly advanced the management of patients with inflammatory bowel disease (IBD), there is a remaining need for efficacious drugs with good safety profiles.

- Homing of leucocytes to the gut mucosa is a promising target for therapeutic intervention in IBD, shown by studies with the $\alpha_{4}$-integrin antibody natalizumab in Crohn's disease and ulcerative colitis.

- However, natalizumab is not available to treat Crohn's disease in Europe given the risk of progressive multifocal leucoencephalopathy (PML).

- To avoid this, more selective strategies targeting the $\alpha_{4} \beta_{7} /$ MAdCAM pathway in the gut would be expected to confer similar efficacy as seen with natalizumab but a better safety profile.

What are the new findings?

- This is the first study of PF-00547,659, a highly specific, fully human anti-MAdCAM $\lg _{2}$ antibody in patients with active ulcerative colitis.

- Study results show that single and multiple doses of PF-00547,659 were safe and well tolerated with no evidence of immunogenicity.

- Furthermore, preliminary efficacy findings were promising with higher response and remission rates for PF-00547,659 as compared to placebo.

\section{How might it impact on clinical practice in the foreseeable future?}

- PF-00547,659 is a promising target for larger phase II studies in ulcerative colitis.

\section{INTRODUCTION}

Biological therapies have an established role in the management of moderate-to-severe inflammatory bowel disease (IBD) that is refractory to conventional treatments. Currently, the only biological treatments for IBD which are licensed worldwide target tumour necrosis factor $\alpha$ (TNF $\alpha$ ) (infliximab, adalimumab and certolizumab pegol for Crohn's disease, and infliximab for ulcerative colitis). While
anti-TNF agents provide a significant advance in the treatment of refractory IBD, with short-term clinical response rates of approximately $60-70 \%$ in ulcerative colitis and Crohn's disease, primary and secondary treatment failure remain a problem for many patients. ${ }^{1-4}$ Furthermore, there are safety concerns with anti-TNF agents, including susceptibility to intracellular opportunistic infections 
such as tuberculosis, and the potential risk of lymphoma and other malignancies. ${ }^{5}$ Therefore, a need remains for efficacious drugs with good safety profiles, to improve patient outcomes in the debilitating conditions of Crohn's disease and ulcerative colitis.

Homing of leucocytes to the gut mucosa is a promising target for therapeutic intervention in IBD, shown by studies with the $\alpha_{4}$-integrin antibody natalizumab in Crohn's disease ${ }^{7-9}$ and ulcerative colitis. ${ }^{10}$ However, the use of natalizumab is limited by well-publicised concerns over the risk of progressive multifocal leucoencephalopathy (PML), ${ }^{11-13}$ an opportunistic infection of the central nervous system (CNS) by the polyomavirus JC virus. ${ }^{14}$ Susceptibility to PML may arise as a result of disruption of immune surveillance in the CNS, which may be mediated in part by homing of $\alpha_{4} \beta_{1}$-positive leucocytes to vascular cell adhesion molecule (VCAM) ${ }^{15-18}$ The effects of natalizumab in the gut likely involve-among other mechanisms (including inhibition of $\alpha_{4} \beta_{1}$ integrin) - another population of cells expressing $\alpha_{4}$-integrin- $\alpha_{4} \beta_{7}$-positive $\left(\alpha_{4} \beta_{7}{ }^{+}\right)$ leucocytes, which bind mucosal addressin cell adhesion molecule (MAdCAM). ${ }^{19-21}$

MAdCAM is expressed predominantly on vascular endothelium in the intestinal lamina propria. ${ }^{22}$ Animal studies confirm the importance of MAdCAM in gut inflammation in colitis, ${ }^{23-25}$ and suggest that VCAM has a comparatively minor role. ${ }^{26-28}$ Selectively targeting the $\alpha_{4} \beta_{7}$ /MAdCAM pathway, to attenuate leucocyte trafficking in the gut without disrupting VCAMmediated leucocyte homing in other organs, would be expected to confer similar efficacy in IBD to that seen with a less selective anti-leucocyte trafficking mechanism, but with potential safety benefits due to the more localised effect. The concept of selectively targeting the $\alpha_{4} \beta_{7} /$ MAdCAM pathway for IBD treatment is supported by animal studies, ${ }^{23} 29$ and initial clinical results with vedolizumab (MLN0002), a humanised monoclonal antibody for $\alpha_{4} \beta_{7}$-integrin. ${ }^{30} 31$

While natalizumab and vedolizumab target integrins, blockade of MAdCAM itself is a gut-specific therapeutic mechanism for IBD. Importantly, for reducing the risk of CNS infections such as PML, immunohistochemistry studies confirm an absence of MAdCAM expression in the human brain. ${ }^{32}$

PF-00547,659 is a highly specific, fully human anti-MAdCAM $\mathrm{IgG}_{2}$ antibody. ${ }^{33}$ We report the first study of PF-00547,659 in humans, in patients with active ulcerative colitis (NCT00928681, http://ClinicalTrials.gov/). The primary objective was to investigate the safety and tolerability of single and multiple doses of PF-00547,659. We also performed exploratory efficacy assessments based on clinical and endoscopic indices of ulcerative colitis activity, and explored effects on number of circulating $\mathrm{CD}^{+}{ }^{+} \alpha_{4} \beta_{7}{ }^{+}$lymphocytes (a mechanistic biomarker), faecal calprotectin (a biomarker for disease activity), and plasma high-sensitivity $\mathrm{C}$ reactive protein (hsCRP; a biomarker for inflammation).

\section{METHODS}

\section{Study design, patients and setting}

This was a randomised, double-blind (sponsor-open), placebocontrolled, dose-escalating, parallel-group study. Patients were assigned to one of six single-dose or five multiple-dose cohorts, and within each cohort were randomised to receive placebo or PF-00547,659. Randomisation was conducted using a sequential numbering system based on the order of patient enrolment.

In the single-dose study phase, patients received single intravenous (IV) infusion of PF-00547,659 at doses of 0.03, 0.1, 0.3,
1.0 or $10 \mathrm{mg} / \mathrm{kg}$ or a single subcutaneous (SC) injection of PF00547,659 at dose of $3.0 \mathrm{mg} / \mathrm{kg}$, or matching placebo. Patients in the multiple-dose phase received three doses, 4 weeks apart, of PF-00547,659 at doses of $0.1,0.3$ or $3.0 \mathrm{mg} / \mathrm{kg}$ IV or 0.3 or $1.0 \mathrm{mg} / \mathrm{kg} \mathrm{SC}$, or placebo (figure 1). PF-00547659 was presented as a sterile, isotonic solution containing $10 \mathrm{mg} / \mathrm{ml} \mathrm{PF-00547659}$ in an acetate buffer solution containing mannitol, Polysorbate and ethylenediaminetetraacetic acid ( $\mathrm{pH}$ 5.5). Sodium chloride solution $0.9 \% \mathrm{w} / \mathrm{v}$ BP was used as the placebo.

Follow-up continued for 12 weeks in the single-dose phase and 16 weeks in the multiple-dose phase. If PF-00547,659 remained detectable in blood plasma at the last clinic visit, follow-up continued at 4-week intervals until drug concentrations fell below the detection limit of $20 \mathrm{ng} / \mathrm{ml}$. To maintain blinding, some patients on placebo were followed up over an extended period.

\section{Inclusion criteria}

Male and female patients aged 18-70 years, with a histologically confirmed diagnosis of ulcerative colitis for at least 3 months prior to study entry, were enrolled. Patients were required to have active ulcerative colitis (total Mayo score $\geq 6$, endoscopic subscore $\geq 2$ ), despite being on stable doses of 5 -aminosalicylic acid (5-ASA) or sulfasalazine for 3 weeks; or azathioprine or 6-mercaptopurine for 3 months, which were to be continued throughout the study; or oral steroids (up to $40 \mathrm{mg} /$ day prednisolone or equivalent) for 2 weeks, which could be tapered at the investigator's discretion.

\section{Exclusion criteria}

Patients were excluded from the study if they had ulcerative colitis confined to proctitis; fulminant colitis; history of malignant neoplasia; renal or hepatic impairment; significant cardiovascular disease in the previous 12 months; hepatitis $B$, hepatitis $\mathrm{C}$ or HIV infection; evidence of pathogenic infection in faecal culture; history of steroid dependence (determined at the investigator's discretion); or allergic disease or sensitivity to heparin.

Patients were also excluded if they had undergone surgery for ulcerative colitis or were likely to require surgery during the study, or if they had used methotrexate, mycophenolate, cyclosporine or biological therapy within 3 months prior to study dosing, interferon or leucocyte apheresis within 12 months, intravenous steroids within 1 month, any rectally administered treatment within 1 week, or had previously used natalizumab or PF-00547,659. Women were excluded if they were pregnant or lactating.

\section{Ethics}

The research protocol was approved by the appropriate institutional review board or independent ethics committee for each study site. All participants gave written informed consent.

\section{Study procedures}

\section{Safety evaluations}

All adverse events (AEs) and the likely relationship to study treatment were recorded. Additional safety evaluations included laboratory tests, vital signs, and 12-lead ECG. To assess whether PF-00547,659 induced an immunogenic response, antidrug antibodies were measured in serum from blood samples taken predose and every 4 weeks up to week 12 .

In the evaluation of efficacy and biomarker data, week 4 of the single-dose cohorts and predose week 4 of the multiple-dose cohorts were combined in the week 4 timepoint assessment. 
Figure 1 Study flow diagram. Patients who discontinued the study due to lack of efficacy or adverse events were considered treatment failures and were included as non-responders in efficacy analyses. AE, adverse event; IV, intravenous; SC, subcutaneous; UC, ulcerative colitis.

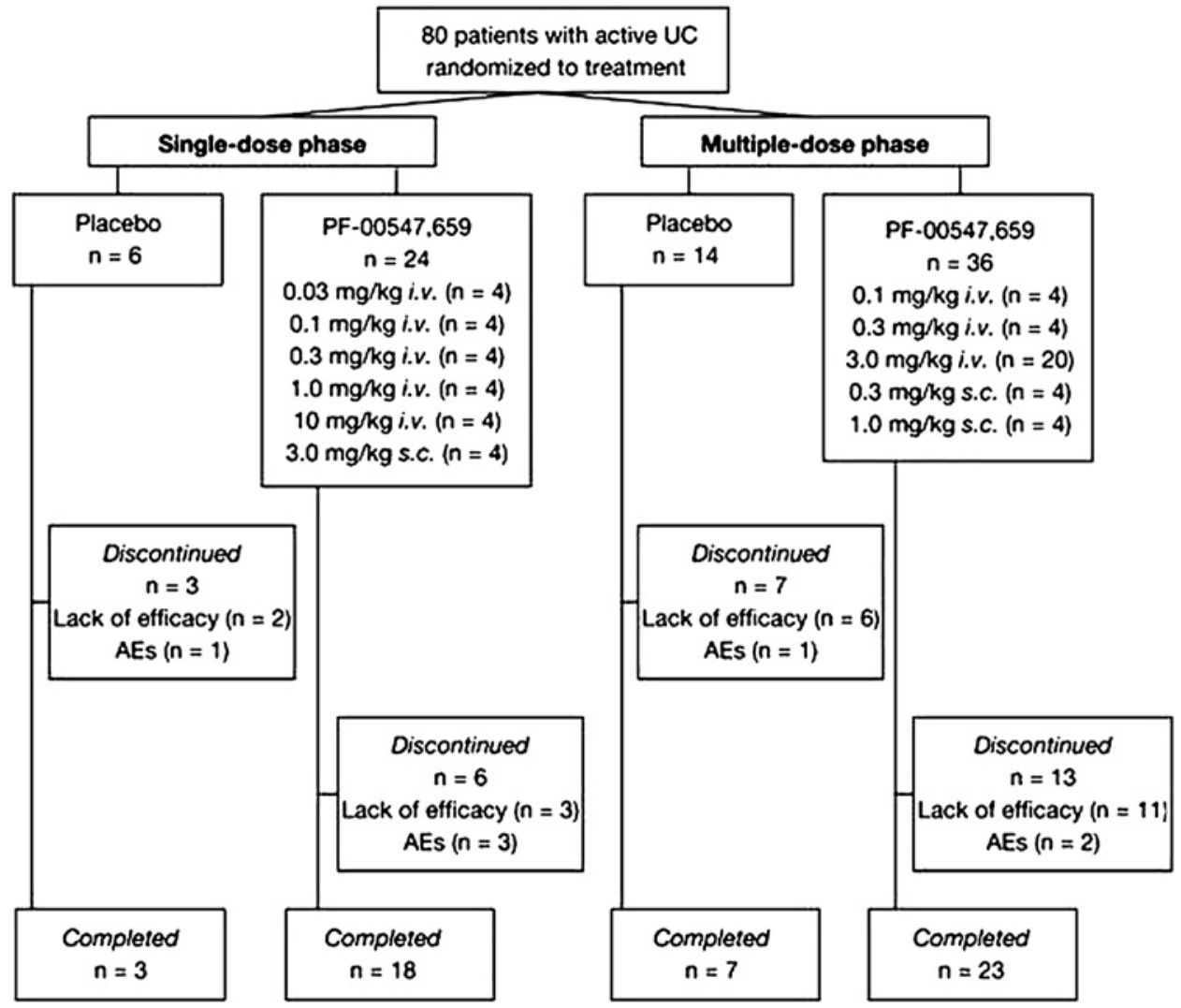

\section{Efficacy evaluations: Mayo scores}

Mayo scores ${ }^{34}$ were derived at week 4 and week 12 from disease diaries completed by patients throughout the study (stool frequency and rectal bleeding components), endoscopic examination by flexible sigmoidoscopy, and the physician's global assessment. Mayo scores were summarised as responder rates (proportion of patients with $\geq 3$-point reduction and $30 \%$ improvement in total Mayo score, and $\geq 1$-point decrease in rectal bleeding subscore or absolute rectal bleeding score of 0 or 1) and remission rates (proportion of patients with total Mayo score $\leq 2$ points with no individual subscore exceeding 1 point). Endoscopic response was defined as $\geq 1$-point improvement in endoscopic subscore, and endoscopic remission as endoscopic subscore of 0 or 1 . The proportion of patients with complete mucosal healing (endoscopic subscore of 0 ) was also quantified.

\section{Measurement of biomarkers}

Feces and blood samples were collected predose and at intervals during 12-16 weeks' follow up, for measurement of faecal calprotectin, hsCRP, and $\alpha_{4} \beta_{7}$-expressing lymphocytes. Fecal calprotectin was quantified by ELISA (ELISA, Calpro AS, Oslo, Norway), while plasma hsCRP was quantified using a standard in vitro diagnostic assay (Tina-Quant, Roche, Mannheim, Germany). Lymphocyte sub-populations expressing $\alpha_{4} \beta_{7^{-}}$ integrin were determined in whole blood by 4-color flow cytometry using anti- $\alpha_{4}$ and anti- $\beta_{7}$ antibodies (FACSCalibur and antibodies, Becton Dickinson, New Jersey, USA) and analysed with FloJo software (Tree Star Inc., Ashland, Oregon, USA).

\section{Statistical methods}

Sample sizes for this first-in-human study were selected to balance the need to minimise exposure of patients to PF-00547,659 with the need to provide adequate safety and tolerability information (primary outcome measure). The study was not powered to detect statistically significant differences in clinical/endoscopic response or remission rates, and biomarkers (secondary outcome measures).

Clinical response and remission rates were calculated for each PF-00547,659 dose strength (IV and SC routes combined) at weeks 4 and 12 to explore the dose-response relationship. Clinical response and remission rates were also calculated for the combined group of all PF-00547,659-treated patients, as were endoscopic response and remission rates. Only patients in the multiple-dose cohort were included in the week 12 analyses. Clinical and endoscopic response and remission rates were compared between PF-00547,659 (all dosages combined) and placebo groups, at weeks 4 and 12, using Fisher's exact test with a one-sided 5\% significance level (SAS; Release 8.02, SAS Institute Inc., Cary, NC, USA). All patients who were randomised and received at least one dose of study treatment were included in efficacy analyses; patients who discontinued due to AEs or lack of efficacy were considered treatment failures and classed as non-responders.

Changes from baseline in natural log-transformed faecal calprotectin and plasma hsCRP levels were compared between PF-00547,659 and placebo at weeks 4 and 12, using an analysis of variance (ANOVA) model that allowed for variation in baseline levels. These results were back-transformed to give point estimates of the percentage changes and associated 95\% CI. Change from baseline in $\mathrm{CD}^{+}{ }^{+} \alpha_{4} \beta_{7}{ }^{+}$and $\mathrm{CD}^{+}{ }^{+} \alpha_{4} \beta_{7}{ }^{-}$lymphocytes was summarised using descriptive statistics (mean, $\mathrm{SD}$ ) for patients receiving each PF-00547,659 dose strength and placebo, at weeks 4 and 12 . For the $\mathrm{CD}^{+} \alpha_{4} \beta_{7}{ }^{+}$and $\mathrm{CD}^{+}{ }^{+} \alpha_{4} \beta_{7}^{-}$lymphocyte analyses, PF-00547,659-treated patients were also subdivided into high-dose $(1-10 \mathrm{mg} / \mathrm{kg})$ and low-dose $(0.03-0.3 \mathrm{mg} / \mathrm{kg})$ groups. 


\section{RESULTS}

\section{Patient demographics and disposition}

Patients were enrolled at 17 sites in Europe from September 2005 to September 2008. In total, 80 patients were assigned to treatment following screening: 30 to single-dose cohorts; 50 to multiple-dose cohorts (figure 1). Twenty-one patients (70\%) completed the single-dose study phase and nine $(30 \%)$ discontinued: five due to lack of efficacy and four due to AEs not considered to be related to study drug. Thirty patients $(60 \%)$ completed the multiple-dose phase of the study and 20 (40\%) discontinued: 17 due to lack of efficacy and three due to AEs; one patient's AEs were considered to be related to the study drug (general physical health deterioration, frequent bowel movements and abnormal laboratory tests, on PF-00547,659 $1 \mathrm{mg} / \mathrm{kg} \mathrm{SC}$ ). The majority of patients were white males (possibly due to entry criteria excluding women of childbearing potential at the start of the study; this was later amended due to low recruitment to allow also females of childbearing potential with adequate contraception), with similar distributions of demographic and baseline clinical characteristics across placebo and active treatment groups (table 1).

\section{Safety and tolerability}

AEs were reported by similar proportions of patients on PF-00547,659 and placebo. The most common AEs affected the gastrointestinal system, including abdominal pain or tenderness; few cases were considered treatment related (table 2). Most AEs were mild or moderate in intensity.

There was no evidence of opportunistic infections arising during PF-00547,659 treatment, within or outside the gastrointestinal system. Overall incidence of gastrointestinal tract infections was low; five patients receiving $\mathrm{PF}-00547,659$ and one receiving placebo reported enteritis/gastroenteritis, but none of the cases were considered by investigators to be related to study treatment. Respiratory tract infections were infrequent. One case (moderate upper respiratory tract infection) was considered potentially related to PF-00547,659 treatment, although the patient was also taking azathioprine, which could have increased susceptibility. Few AEs affecting the central nervous system (CNS) (mostly dizziness) were reported, with the majority of cases not considered to be treatment related.

There were no deaths during the study. Three patients reported nine serious AEs (SAEs) within the 16-week study (one patient in each of the placebo, $3 \mathrm{mg} / \mathrm{kg}$ IV and $1 \mathrm{mg} / \mathrm{kg} \mathrm{SC}$ multiple-dose groups). Only the patient receiving PF-00547,659 $1 \mathrm{mg} / \mathrm{kg}$ SC had SAEs that were investigator-assessed as potentially related to treatment: rectal haemorrhage, general physical health deterioration, joint (ankle) abscess, wound infection (abdominal wall wound from proctocolectomy undertaken upon worsening of ulcerative colitis), and abnormal laboratory tests (elevated leucocyte count; low haemoglobin); this patient discontinued the study. SAEs were recorded for six more patients at follow-up visits after study end; these AEs were considered to be related to underlying ulcerative colitis or other illnesses. Laboratory test abnormalities did not suggest any treatment- or dose-related patterns in changes in any parameter.

There was no evidence of an immunogenic response to the drug as no anti-drug antibodies were detected in the presence of the drug, or 1 month after the last injection, and no injection site reactions were observed. Measurements at later time points after complete disappearance of the drug would be needed to

Table 1 Demographic and baseline characteristics

\begin{tabular}{|c|c|c|}
\hline Characteristic & $\begin{array}{l}\text { Placebo (single and multiple } \\
\text { dose cohorts) }(\mathrm{N}=20)\end{array}$ & $\begin{array}{l}\text { PF-00547,659 (all active } \\
\text { treatment groups) }(\mathrm{N}=60)\end{array}$ \\
\hline \multicolumn{3}{|l|}{ Gender } \\
\hline Male & $17(85 \%)$ & $52(87 \%)$ \\
\hline \multicolumn{3}{|l|}{ Race } \\
\hline White & $20(100 \%)$ & $58(97 \%)$ \\
\hline Asian & 0 & $1(2 \%)$ \\
\hline Hispanic & 0 & $1(2 \%)$ \\
\hline Age (years), mean (SD) & $47.9(14.8)$ & $45.1(13.1)$ \\
\hline Weight $(\mathrm{kg})$, mean $(\mathrm{SD})$ & $83.7(13.1)$ & $80.2(14.7)$ \\
\hline $\begin{array}{l}\text { Disease duration (years), median } \\
\text { (range) }\end{array}$ & $6.5(0.3-23.5)$ & $6.2(0.6-41.4)$ \\
\hline \multicolumn{3}{|l|}{ Prior drug treatment for ulcerative colitis } \\
\hline Mesalazine & $17(85 \%)$ & $47(78 \%)$ \\
\hline Azathioprine & $6(30 \%)$ & $22(37 \%)$ \\
\hline Infliximab & $4(20 \%)$ & $4(7 \%)$ \\
\hline \multicolumn{3}{|c|}{ Concomitant drug treatment for ulcerative colitis during the study } \\
\hline Mesalazine/prodrugs* & $18(90 \%)$ & $50(83 \%)$ \\
\hline Azathioprine & $4(20 \%)$ & $19(32 \%)$ \\
\hline Mercaptopurine & $1(5 \%)$ & $1(2 \%)$ \\
\hline Steroids $\dagger$ & $8(40 \%)$ & $30(50 \%)$ \\
\hline Baseline total Mayo score, median (IOR) & $7.5(7.0-8.5)$ & $8.5(7.0-9.5)$ \\
\hline \multirow{2}{*}{$\begin{array}{l}\text { Baseline faecal calprotectin }(\mathrm{mg} / \mathrm{kg}) \\
\text { geometric mean }(95 \% \mathrm{Cl})\end{array}$} & $\mathrm{N}=20$ & $\mathrm{~N}=57$ \\
\hline & 733 (340 to 1578$)$ & $629(425$ to 932$)$ \\
\hline \multirow[t]{2}{*}{ Baseline hsCRP (mg/dl), mean (SD) } & $\mathrm{N}=19$ & $\mathrm{~N}=58$ \\
\hline & $10.3(11.2)$ & $10.8(21.4)$ \\
\hline
\end{tabular}

When the study commenced all women of childbearing potential were excluded; this criterion was subsequently relaxed to increase enrolment of younger women and make the study population more representative of patients with ulcerative colitis seen in the clinic, providing women of childbearing potential used at least two contraceptive methods.

*Predominantly mesalazine; also includes sulfasalazine, olsalazine.

†Includes prednisolone, methylprednisolone, prednisone, beclometasone, betamethasone, cortisone acetate, hydrocortisone.

hsCRP, high-sensitivity $C$ reactive protein; IQR, interquartile range. 
Table 2 Adverse events occurring in $\geq 2$ patients in placebo or PF-00547,659 combined groups (single- and multiple-dose study phases combined)

\begin{tabular}{|c|c|c|}
\hline \multirow[b]{2}{*}{ System organ class/preferred term } & \multicolumn{2}{|c|}{$\begin{array}{l}\text { Percentage of patients with all- } \\
\text { cause (treatment-related) adverse } \\
\text { events }\end{array}$} \\
\hline & $\begin{array}{l}\text { Placebo } \\
(\mathrm{N}=20)\end{array}$ & $\begin{array}{l}\text { PF-00547,659 } \\
(\mathrm{N}=60)\end{array}$ \\
\hline Any adverse event & $75(20)$ & $82(37)$ \\
\hline Severe adverse events & $10(0)$ & $13(5)$ \\
\hline Headache & $10(5)$ & $30(13)$ \\
\hline Abdominal pain* & $25(0)$ & $20(0)$ \\
\hline Worsening of ulcerative colitis & $15(0)$ & $13(0)$ \\
\hline Fatigue & $10(10)$ & $13(5)$ \\
\hline Arthralgia & $10(0)$ & $10(3)$ \\
\hline Influenza/influenza-like illness & $0(0)$ & $10(2)$ \\
\hline Gastroenteritis/enteritis & $5(0)$ & $8(0)$ \\
\hline Anaemia $†$ & $0(0)$ & $8(2)$ \\
\hline Nasopharyngitis & $10(0)$ & $7(2)$ \\
\hline Respiratory tract infection $\ddagger$ & $0(0)$ & $7(2)$ \\
\hline Nausea & $10(0)$ & $5(3)$ \\
\hline Dizziness & $5(0)$ & $5(3)$ \\
\hline Peripheral oedema & $0(0)$ & $5(2)$ \\
\hline Back pain & $15(0)$ & $3(0)$ \\
\hline Vomiting & $5(0)$ & $3(0)$ \\
\hline Erythema & $5(5)$ & $3(0)$ \\
\hline Insomnia (initial) & $0(0)$ & $3(3)$ \\
\hline Eczema & $0(0)$ & $3(3)$ \\
\hline Pruritis & $0(0)$ & $3(3)$ \\
\hline Hot flush & $0(0)$ & $3(3)$ \\
\hline Pain (not otherwise specified) & $0(0)$ & $3(0)$ \\
\hline
\end{tabular}

*Includes preferred terms abdominal pain, upper abdominal pain and lower abdominal pain. tIncludes preferred terms anaemia and iron deficiency anaemia.

łIncludes preferred terms respiratory tract infection and upper respiratory tract infection.

definitively rule out anti-drug antibodies, but these samples are not available.

\section{Efficacy results}

\section{Mayo scores}

Overall response rates were higher with PF-00547,659 than placebo at both week $4(52 \%$ vs $32 \%$, respectively; $p=0.102)$ and week 12 (42\% vs $21 \%$, respectively; $p=0.156$; multiple-dose cohort only), but these differences did not reach statistical significance (figure 2A). Remission rates were similar in PF00547,659 and placebo groups at week 4 (13\% and 11\%, respectively), but it may take longer to achieve full remission than simply response, and by week 12 remission rates had risen to $22 \%$ with PF-00547,659, while no patients on placebo remained in remission (figure $2 \mathrm{~B}$ ). The difference in week 12 remission rates between PF-00547,659 and placebo approached, but did not reach statistical significance $(p=0.056)$. When separate PF-00547,659 dose groups were considered, there was no clear pattern of increasing response or remission rate with increasing PF00547,659 dose (figure 3). Endoscopic response and remission rates were numerically, but not statistically higher, at both timepoints, with PF-00547,659 than placebo (figure 2C,D). Although complete mucosal healing rates were similar with PF00547,659 and placebo at week $4(10 \%(6 / 60)$ vs $11 \%(2 / 19)$, respectively), by week $12,14 \%(5 / 36)$ of patients on active treatment had complete mucosal healing compared with $0 \%(0 /$ 14) of those on placebo. Examination of individual Mayo component scores indicated that a reduction in rectal bleeding, as well as endoscopic improvement/healing, contributed towards the improvements in overall Mayo scores seen with PF-00547,659.

\section{Biomarkers}

The reduction in mean faecal calprotectin from baseline was significantly higher with PF-00547,659 than with placebo at week 4 (63\% vs $18 \%$, respectively) and of borderline significance at week 12 (73\% vs 34\%, respectively) (figure 4A). At the individual patient level, there was a trend for a high proportion of patients in the PF-00547,659 group to have reductions in faecal calprotectin from baseline to week 4 or week 12 (data not shown). In the placebo group, individual patient responses were highly variable and there was no clear trend for a reduction in faecal calprotectin from baseline at either timepoint.

Clinically meaningful changes in plasma hsCRP could not be detected as baseline levels were close to normal values (table 1). Individual changes in plasma hsCRP from baseline with both PF00547,659 and placebo were also highly variable, with no significant differences in mean values between the two treatments at week $4(-14 \%$ vs $-28 \%$, respectively) or $12(-57 \%$ vs $7 \%$, respectively).

There was a trend for an increase from baseline in the number of circulating $\mathrm{CD}^{+}{ }^{+} \alpha_{4} \beta_{7}{ }^{+}$lymphocytes in patients receiving PF00547,659 , but not in patients receiving placebo (table 3); however, this was not statistically significant due to a large inter-subject variability. The effect was sustained at 4 weeks in both the high-dose $(1-10 \mathrm{mg} / \mathrm{kg})$ and low-dose $(0.03-0.3 \mathrm{mg} /$ $\mathrm{kg}) \mathrm{PF}-00547,659$ groups (figure 4B). The mean number of CD4 ${ }^{+}$ $\alpha_{4} \beta_{7}{ }^{-}$cells in the high- and low-dose PF-00547,659 groups, and the placebo group, remained close to baseline values throughout the study (figure 4C). For both cell types, individual responses were subject to considerable variation.

\section{DISCUSSION}

Blocking MAdCAM is a rational mechanism of action for therapeutic intervention in IBD. MAdCAM represents an organspecific target, as expression is restricted mainly to gastrointestinal tract mucosa. ${ }^{22}$ This organ specificity may translate to a favourable safety profile; in particular, the absence of MAdCAM in the brain microvasculature ${ }^{32}$ suggests that drugs acting on MAdCAM would not impact the body's ability to respond to CNS infections such as PML.

Indeed, this first-in-human trial of PF-00547,659 had a relatively low incidence of non-gastrointestinal AEs. Gastrointestinal AEs were common in both PF-00547,659 and placebo groups, owing to the disease under study, and most AEs were not considered to be treatment related. The majority of SAEs occurred after follow-up and were related to underlying disease rather than study drug. While nine patients (30\%) discontinued the single-dose phase and 20 (40\%) discontinued the multipledose phase of the study, only seven withdrew due to AEs. Moreover, only one of these patient's AEs were considered to be related to the study drug. Overall, PF-00547,659 had an AE profile similar to placebo, and no safety concerns emerged in laboratory tests or other safety monitoring.

Biological therapy is often associated with immunogenic reactions, development of antidrug antibodies, which diminish treatment response and can lead to infusion/injection site reactions. PF-00547,659 is a fully human monoclonal antibody developed using Abgenix XenoMouse ${ }^{\mathrm{TM}}$ technology (Amgen, Thousand Oaks, California, USA), a platform that has yielded antibodies with low intrinsic immunogenicity. In this study, no antidrug antibodies were detected during treatment up to week 12 for all patients, and no injection site reactions were observed. Longer-term studies, involving a much larger number of patients, are required to confirm a lack of immunogenicity with 
Figure 2 Improvement in signs and symptoms of ulcerative colitis with PF-00547,659: overall clinical response $\left({ }^{*}\right)$ and remission $(\dagger)$ rates and endoscopic response (‡) and remission $(\S)$ rates based on Mayo scores at week 4 and 12. (A) $\geq 3$-point reduction and $30 \%$ improvement in total Mayo score (all components including endoscopy $\geq 1$ point), and a decrease in rectal bleeding subscore, or absolute rectal bleeding score of 0 or 1 . (B) Total Mayo score $\leq 2$ points with no individual subscore $>1$ point. (C) $\geq 1$ point improvement in Mayo endoscopic subscore. (D) Mayo endoscopic subscore of 0 or 1. $p$ Values obtained using one-sided Fisher's exact test to test the probability that active treatment is associated with higher response/ remission rates than placebo. Week 4 data include all patients in single-dose cohort and data for assessments following the first dose for all patients in multiple-dose cohorts. Week 12 data include patients in the multiple-dose cohort only.
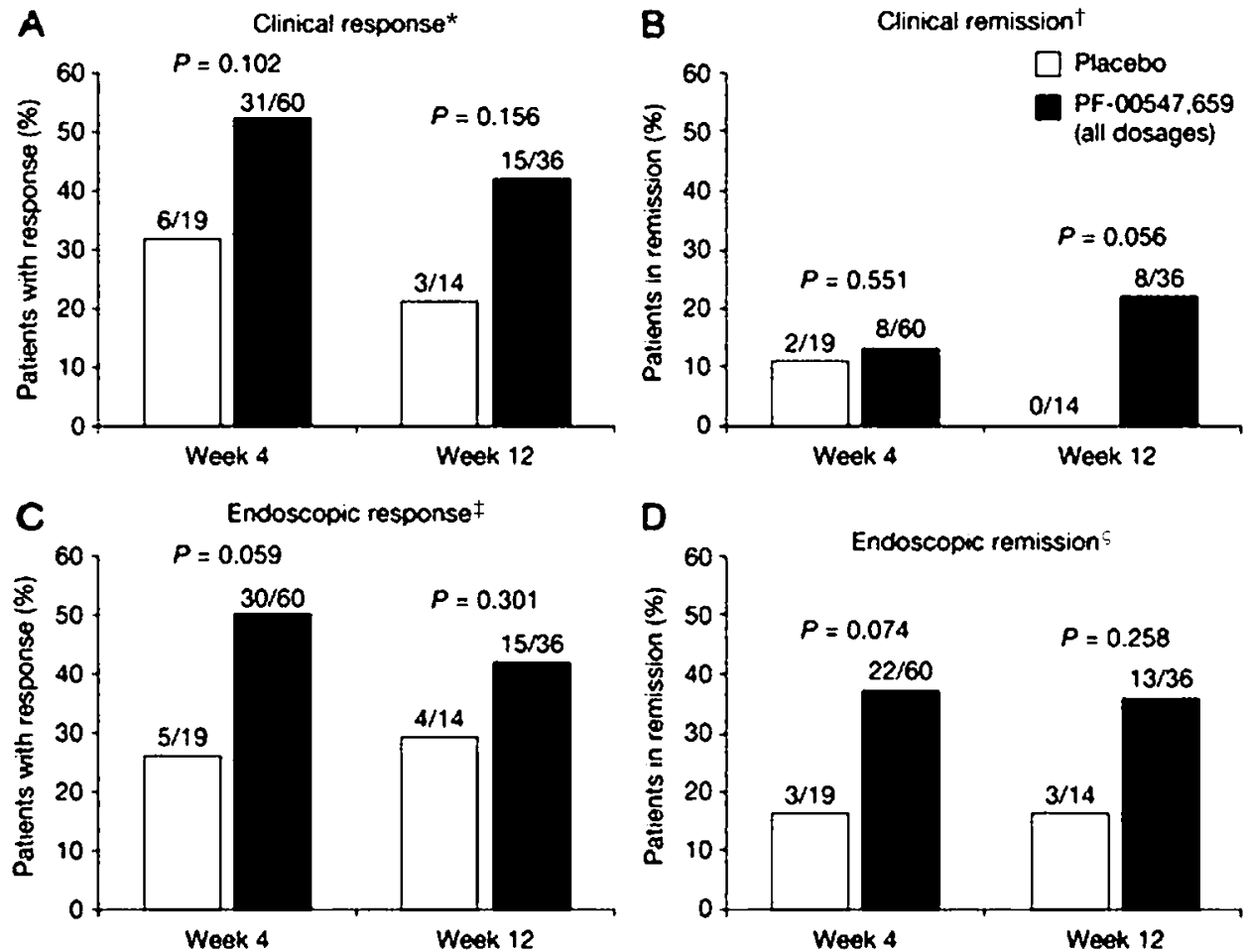

prolonged treatment (administered at clinically relevant doses) and assess other aspects of long-term safety, including risk of opportunistic infections, which only tend to become evident with extended treatment. Biological agents for IBD are likely to be subject to scrutiny in this regard following cases of PML with long-term natalizumab therapy. Up to $80 \%$ of adults carry the $\mathrm{JC}$ virus in a latent form, after being exposed during childhood. The virus resides in the kidneys, bone marrow and the gastrointestinal tract and re-activation, most likely via the haematogenic route to the brain, causes PML. It is not clear if defective homing of cytotoxic $T$ cells to the brain or the appearance of more virulent JC virus in the brain contribute to the risk of PML as seen after natalizumab therapy.

This study investigated the preliminary efficacy of PF-00547,659 in patients whose ulcerative colitis is not controlled with conventional therapy and found that, within small sample size limitations, PF-00547,659 produced some potential benefits over placebo on clinical and endoscopic endpoints. However, no statistical differences between PF-00547,659 and placebo were reported for any efficacy endpoints. Overall Mayo responder rates were approximately 40-50\% with PF-00547,659. No clear dose-response relationship was observed with PF-00547,659,
Figure 3 Clinical response $(A)$ and remission $(B)$ rates (based on total Mayo score) at weeks 4 and 12 by PF-00547,659 dose.
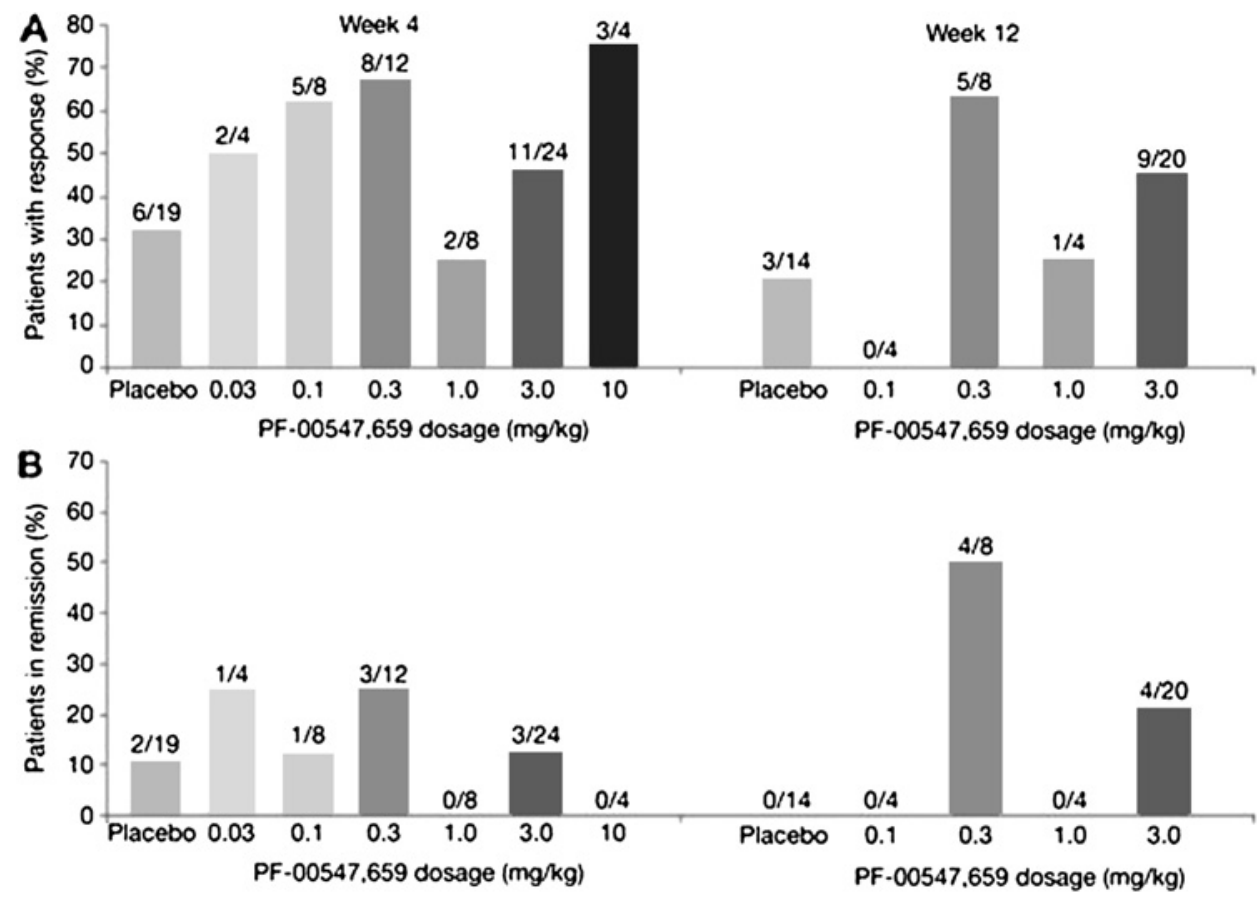
Figure 4 Mean change from baseline in biomarkers following dosing with PF-00547,659 or placebo: faecal calprotectin (A); $\mathrm{CD}^{+} \alpha_{4} \beta_{7}$-positive lymphocytes (B); $\mathrm{CD}^{+}{ }^{+} \alpha_{4} \beta_{7}$-negative lymphocytes (C). (A) Baseline adjusted geometric mean and associated $95 \% \mathrm{Cl}$ are presented as a percentage change from baseline. ( $B$ and $C$ ) Descriptive statistics only. $N$ numbers were variable over the 28 days.

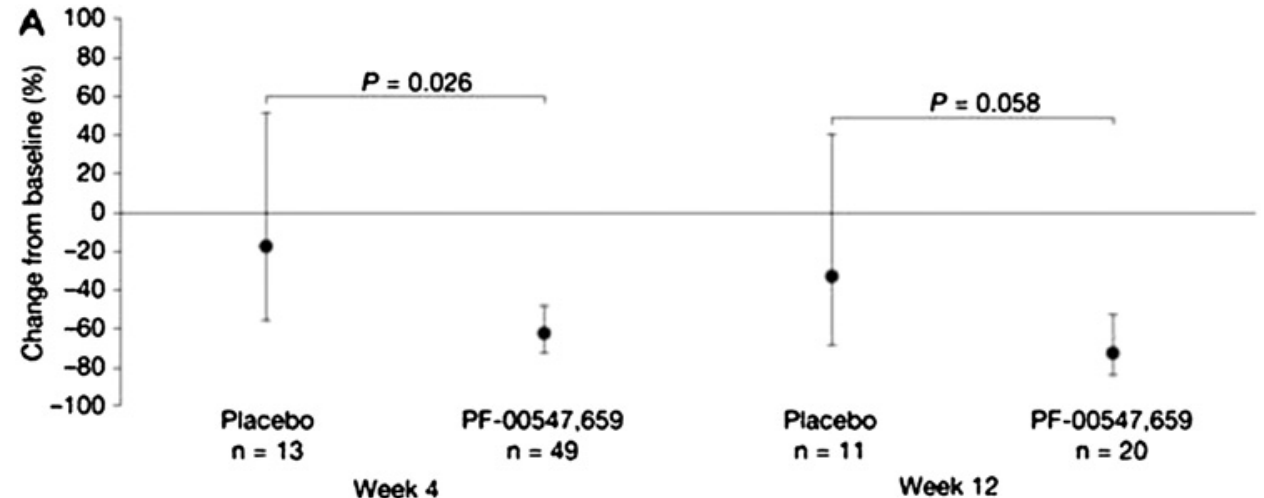

Week 4

Week 12
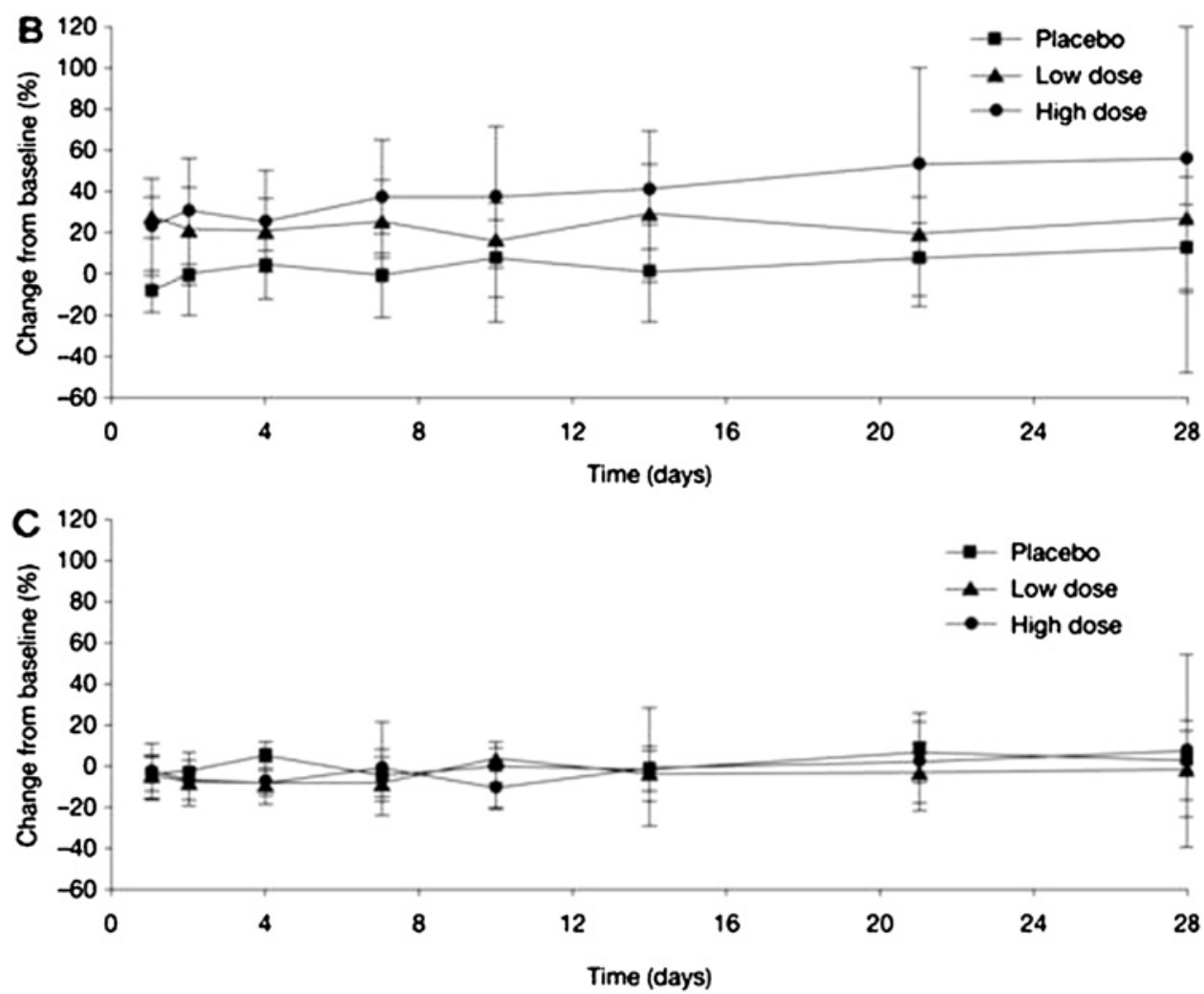

although small groups (most doses administered to four patients) and limited sensitivity of the clinical and endoscopic endpoints confounded full exploration of dose-response relationships within this initial study. The high discontinuation rate due to lack of efficacy (22/80) was not surprising for a patient population with a fairly extensive, multidrug treatment history and advanced disease that was not adequately controlled with conventional medications.

Results of biomarker assays supported the clinical findings of this study. Levels of faecal calprotectin, which reflects disease activity and is a good predictor of disease course in ulcerative

Table 3 Mean change in $\mathrm{CD}^{+} \alpha_{4} \beta_{7}$-positive lymphocytes from baseline in whole blood following dosing with PF-00547,659 or placebo

\begin{tabular}{llllll}
\hline & \multicolumn{2}{l}{ Placebo } & & \multicolumn{2}{l}{ PF-00547,659 } \\
\cline { 2 - 3 } \cline { 5 - 6 } & N & $\begin{array}{c}\text { \% change, } \\
\text { mean (SD) }\end{array}$ & & N & $\begin{array}{l}\text { \% change, } \\
\text { mean (SD) }\end{array}$ \\
\hline Week 4* & 8 & $12.7(20.6)$ & & 32 & $44.6(68.9)$ \\
Week 12† & 5 & $-0.4(15.7)$ & & 10 & $46.5(41.6)$
\end{tabular}

${ }^{*}$ Combined data for single- and multiple-dose cohorts following the first dose.

†Multiple-dose cohorts only. colitis, ${ }^{35-37}$ declined in patients treated with PF-00547,659, and were significantly reduced with PF-00547,659 relative to placebo at week 4 . An increase in the number of $\mathrm{CD}^{+}{ }^{+} \alpha_{4} \beta_{7}{ }^{+}$lymphocytes following PF-00547,659 administration, with no change in $\mathrm{CD}^{+}{ }^{+} \alpha_{4} \beta_{7}^{-}$cell numbers, was consistent with MAdCAM blockade, and reflects the expected pharmacology that has been reported in primate studies with PF-00547,659. ${ }^{33}$ It should be noted, nonetheless, that individual lymphocyte responses were subject to huge variation. Lack of change in $\alpha_{4} \beta_{7}^{-}$cell numbers provided validation for the sensitivity of the assay to any potential drug-related effects. As mean hsCRP levels were close to normal levels at baseline and post-treatment changes were subject to considerable variation, hsCRP was not considered a useful biomarker for ulcerative colitis inflammation in this study.

This first-in-human study was conducted in patients with ulcerative colitis, but the drug's mechanism, blocking MAdCAM to attenuate lymphocyte migration to the gut mucosa, would also be expected to be effective in Crohn's disease. The next steps in development of the compound for either indication should include fully powered dose-ranging studies, this time applying an even gender distribution (which was skewed in the 
present study due to the initial exclusion of women of childbearing potential). Dose selection for such studies can be guided by pharmacokinetic profiles, which indicate that MAdCAM becomes fully saturated at PF-00547,659 doses of $1 \mathrm{mg} / \mathrm{kg}$ or higher, ${ }^{38}$ and levels of $\mathrm{CD}^{+}{ }^{+} \alpha_{4} \beta_{7}{ }^{+}$lymphocytes, which showed some differentiation of dose effect. Longer-term studies are needed, to assess efficacy in maintenance as well as induction of remission, and to confirm the apparently positive safety profile observed in this study.

In conclusion, the favourable short-term (typically 12-16week) safety profile and preliminary efficacy results observed with the MAdCAM antibody PF-00547,659 in this first-inhuman study pave the way for a further longer-term investigation of clinically relevant doses in larger numbers of patients, as will be necessary to establish the potential role of PF-00547,659 in the treatment of IBD.

Funding This study was sponsored by Pfizer Inc.

Competing interests SV has received consulting fees $(<\$ 10,000 /$ year $)$ from Schering-Plough, speaker fees $(<\$ 10,000 /$ year) from Schering-Plough, UCB and Ferring, and grant support $(€ 65,000)$ from UCB. JFD has received speaker fees $(<\$ 10,000 /$ year) from Ferring and Roche. AL has received consulting fees $(<\$ 10,000 /$ year) from UCB, speaker fees $(<\$ 10,000 /$ year $)$ from Abbott, Essex and the Falk Foundation, and grant support from Wolff Pharma ( $\$ 80,000$ in 2008), IZKF (institutional research grant of $\$ 200,000$ covering the period 2006-2008) and the German Research Foundation (DFG; $\$ 70,000$ over 2008/9). JP has received consulting fees $(<\$ 10,000 /$ year $)$ from Schering-Plough, Abbott and Ferring, speaker fees $1<\$ 10,000 /$ year) from Schering-Plough and Abbott, and grant support from the Spanish Ministry of Science and Innovation (\$175,000 over 2007/9) and Schering-Plough (\$125,000 over 2008/9). SG has received speaker fees $(<\$ 10,000 /$ year) from Schering-Plough, Centocor, UCB and Abbott, speaker fees $(<\$ 10,000 /$ year) from Schering-Plough, Procter and Gamble and (>\$10,000/year) Abbott, and grant support $(\$ 90,000$ over 2006-2007) from Schering-Plough. WN has equity/stock ownership $(>\$ 10,000)$ in Pfizer Ltd and Johnson \& Johnson, and is an employee of Pfizer Ltd. GB and J Spanton have equity/stock ownership $(>\$ 10,000)$ in Pfizer Ltd and are employees of Pfizer Ltd. SWM has equity/stock ownership $(>\$ 10,000)$ in Pfizer Ltd and Amgen, and is an employee of Pfizer Ltd. US has no financial disclosures to declare. J Sirotiakova has no competing interests.

Patient consent Obtained.

Ethics approval The research protocol was approved by the appropriate institutional review board or independent ethics committee for each study site. All participants gave written informed consent.

Contributors All authors participated in the acquisition and interpretation of the data.

Provenance and peer review Not commissioned; externally peer reviewed.

\section{REFERENCES}

1. Rutgeerts P, Sandborn WJ, Feagan BG, et al. Infliximab for induction and maintenance therapy for ulcerative colitis. N Engl J Med 2005;353:2462-76.

2. Hanauer SB, Feagan BG, Lichtenstein GR, et al. Maintenance infliximab for Crohn's disease: the ACCENT I randomised trial. Lancet 2002;359:1541-9.

3. Schreiber S, Khaliq-Kareemi M, Lawrance IC, et al. Maintenance therapy with certolizumab pegol for Crohn's disease. N Engl J Med 2007;357:239-50.

4. Colombel JF, Sandborn WJ, Rutgeerts $P$, et al. Adalimumab for maintenance of clinical response and remission with Crohn's disease: the CHARM trial. Gastroenterology 2007;132:52-65.

5. Caviglia R, Boskoski I, Cicala M. Long-term treatment with infliximab in inflammatory bowel disease: safety and tolerability issues. Expert Opin Drug Saf 2008; 7:617-32

6. Lin J, Ziring D, Desai S, et al. TNF $\alpha$ blockade in human diseases: an overview of efficacy and safety. Clin Immunol 2008;126:13-30.

7. Gordon FH, Lai CW, Hamilton MI, et al. A randomized placebo-controlled trial of a humanized monoclonal antibody to alpha-4 integrin in active Crohn's disease. Gastroenterology 2001;121:268-74.

8. Ghosh S, Goldin E, Gordon FH, et al. Natalizumab for active Crohn's disease. N Engl J Med 2003:348:24-32.

9. Sandborn WJ, Colombel JF, Enns R, et al. Natalizumab induction and maintenance therapy for Crohn's disease. N Engl J Med 2005;353:1912-25.
10. Gordon FH, Hamilton Ml, Donoghue S, et al. A pilot study of treatment of active ulcerative colitis with natalizumab, a humanized monoclonal antibody to alpha-4 integrin. Aliment Pharmacol Ther 2002;16:699-705.

11. Langer-Gould A, Atlas SW, Green AJ, et al. Progressive multifocal leukoencephalopathy in a patient treated with natalizumab. $N$ Engl J Med 2005;353:375-81.

12. Kleinschmidt-DeMasters BK, Tyler KL. Progressive multifocal leukoencephalopathy complicating treatment with natalizumab and interferon beta-1a for multiple sclerosis. N Engl J Med 2005;353:369-74.

13. Van Assche G, Van Ranst M, Sciot R, et al. Progressive multifocal leukoencephalopathy after natalizumab therapy for Crohn's disease. N Engl J Med 2005;353:362-8.

14. Major EO, Amemiya K, Tornatore CS, et al. Pathogenesis and molecular biology of progressive multifocal leukoencephalopathy, the JC virus-induced demyelinating disease of the human brain. Clin Microbiol Rev 1992;5:49-73.

15. Stüve 0, Marra CM, Jerome $\mathrm{KR}$, et al. Immune surveillance in multiple sclerosis patients treated with natalizumab. Ann Neurol 2006;59:743-7.

16. Stüve $\mathbf{0}$. The effects of natalizumab on the innate and adaptive immune system in the central nervous system. J Neurol Sci 2008;274:39-41.

17. Niino M, Bodner C. Simard ML, et al. Natalizumab effects on immune cell responses in multiple sclerosis. Ann Neurol 2006;59:748-54.

18. Li YY, Perez HD, Zollner TM. Fatalities in natalizumab treatment - a 'no go' for leukocyte recirculation approaches? Expert Opin Ther Targets 2006;10:489-99.

19. Guagnozzi D, Caprilli R. Natalizumab in the treatment of Crohn's disease. Biologics 2008:2:275-84.

20. Hamann A, Andrew DP, Jablonski-Westrich D, et al. Role of alpha 4-integrins in lymphocyte homing to mucosal tissues in vivo. J Immunol 1994;152:3282-93.

21. Berlin C, Berg EL, Briskin MJ, et al. Alpha 4 beta 7 integrin mediates lymphocyte binding to the mucosal vascular addressin MAdCAM-1. Cell 1993;74:185-95.

22. Briskin M, Winsor-Hines D, Shyjan A, et al. Human mucosal addressin cell adhesion molecule-1 is preferentially expressed in intestinal tract and associated lymphoid tissue. Am J Pathol 1997;151:97-110.

23. Picarella D, Hurlbut $P$, Rottman J, et al. Monoclonal antibodies specific for beta 7 integrin and mucosal addressin cell adhesion molecule-1 (MAdCAM-1) reduce inflammation in the colon of SCID mice reconstituted with CD45RBhigh CD4 ${ }^{+}$T cells J Immunol 1997;158:2099-106.

24. Hokari R, Kato S, Matsuzaki K, et al. Involvement of mucosal addressin cell adhesion molecule-1 (MAdCAM-1) in the pathogenesis of granulomatous colitis in rats. Clin Exp Immunol 2001;126:259-65.

25. Farkas S, Hornung M, Sattler $\mathrm{C}$, et al. Blocking MAdCAM-1 in vivo reduces leukocyte extravasation and reverses chronic inflammation in experimental colitis. Int J Colorectal Dis 2006;21:71-8.

26. Kato S, Hokari R, Matsuzaki K, et al. Amelioration of murine experimental colitis by inhibition of mucosal addressin cell adhesion molecule-1. J Pharmacol Exp Ther 2000;295:183-9.

27. Shigematsu T, Specian RD, Wolf RE, et al. MAdCAM mediates lymphocyteendothelial cell adhesion in a murine model of chronic colitis. Am J Physiol Gastrointest Liver Physiol 2001;281:G1309-15.

28. Teramoto $\mathbf{K}$, Miura S, Tsuzuki $Y$, et al. Increased lymphocyte trafficking to colonic microvessels is dependent on MAdCAM-1 and $\mathrm{C}-\mathrm{C}$ chemokine $\mathrm{mLARC} / \mathrm{CC} 20$ in DSS-induced mice colitis. Clin Exp Immunol 2005;139:421-8.

29. Goto A, Arimura Y, Shinomura Y, et al. Antisense therapy of MAdCAM-1 for trinitrobenzenesulfonic acid-induced murine colitis. Inflamm Bowel Dis 2006;12:758-65

30. Feagan BG, Greenberg GR, Wild G, et al. Treatment of ulcerative colitis with a humanized antibody to the $\alpha 4 \beta 7$ integrin. N Engl J Med 2005;352:2499-507.

31. Feagan BG, Greenberg GR, Wild G, et al. Treatment of active Crohn's disease with MLN0002, a humanized antibody to the $\alpha 4 \beta 7$ integrin. Clin Gastroenterol Hepatol 2008;6:1370-7.

32. Allavena R, Noy S, Andrews M, et al. CNS elevation of vascular and not mucosa addressin cell adhesion molecules in patients with multiple sclerosis. Am J Pathol 2010;176:556-62.

33. Pullen N, Molloy E, Carter D, et al. Pharmacological characterization of PF-00547659, an anti-human MAdCAM monoclonal antibody. Br J Pharmacol 2009;157:281-93.

34. Schroeder KW, Tremaine WJ, IIstrup DM. Coated oral 5-aminosalicylic acid therapy for mildly to moderately active ulcerative colitis. N Engl J Med 1987;317:1625-9.

35. Xiang JY, Ouyang $\mathrm{Q}$, Li GD, et al. Clinical value of fecal calprotectin in determining disease activity of ulcerative colitis. World J Gastroenterol 2008:14:53-7.

36. Costa F, Mumolo MG, Ceccarelli L, et al. Calprotectin is a stronger predictive marke of relapse in ulcerative colitis than in Crohn's disease. Gut 2005;54:364-8.

37. Ho GT, Lee HM, Brydon G, et al. Fecal calprotectin predicts the clinical course of acute severe ulcerative colitis. Am J Gastroenterol 2009;104:673-8.

38. Martin SW, Magnusson MO, Matthews IT, et al. Mechanistic population pharmacokinetics (PK) model of PF-00547659, a fully human IgG2 anti-MAdCAM antibody, in ulcerative colitis patients: results of a first in human $(\mathrm{FIH})$ study. Gastroenterology 2009;136(Suppl 1):A-641. 


\section{GUT}

The mucosal addressin cell adhesion molecule antibody PF-00547,659 in ulcerative colitis: a randomised study

Séverine Vermeire, Subrata Ghosh, Julian Panes, Jens F Dahlerup, Andreas Luegering, Jana Sirotiakova, Ulrike Strauch, Gary Burgess, Jacqueline Spanton, Steven W Martin and Wojciech Niezychowski

Gut 2011 60: 1068-1075 originally published online February 11, 2011 doi: $10.1136 /$ gut.2010.226548

Updated information and services can be found at:

http://gut.bmj.com/content/60/8/1068

\section{These include:}

References This article cites 38 articles, 6 of which you can access for free at: http://gut.bmj.com/content/60/8/1068\#BIBL

Email alerting Receive free email alerts when new articles cite this article. Sign up in the service box at the top right corner of the online article.

Topic Articles on similar topics can be found in the following collections Collections

Ulcerative colitis (1113)

\section{Notes}

To request permissions go to:

http://group.bmj.com/group/rights-licensing/permissions

To order reprints go to:

http://journals.bmj.com/cgi/reprintform

To subscribe to BMJ go to:

http://group.bmj.com/subscribe/ 